DOI: http://dx.doi.org/10.1590/1981-7746-sol00186

\title{
PROJOVEM URBANO: A PRECARIZAÇÃO MASCARADA SOB O SIGNO DA FORMAÇÃO INICIAL PARA O TRABALHO SIMPLES
}

\author{
PROJOVEM URBANO: THE MASSED PRECARIZATION UNDER \\ THE SIGN OF INITIAL TRAINING FOR SIMPLE WORK
}

\author{
Leandro Gaspar (iD) (https://orcid.org/0000-0002-9874-1178) ${ }^{1}$, \\ ${ }^{1}$ Universidade de São Paulo, Programa de Pós-Graduação em Educação, São Paulo, São Paulo, Brasil. \\ <leandrogaspar@usp.br>
}

Resumo A primeira década do século XXI é particularmente importante para a educação brasileira por registrar o crescimento das políticas de governo direcionadas aos jovens e adultos trabalhadores. Especificamente, após a criação do Programa Nacional de Inclusão de Jovens (2005), a relação entre as políticas de governo e a educação profissional tornam-se parte da promessa integradora da educação hegemônica para a redução das desigualdades sociais. Nessa direção, o Projovem Urbano passa a instituir, em suas práticas pedagógicas, a formação inicial em um arco de ocupações para que os trabalhadores consigam responder às demandas da reestruturação produtiva, reduzindo, assim, a crise do desemprego. O objetivo deste estudo foi apreender a realidade concreta sobre a formação inicial para o trabalho, com base em um quadro categorial, composto por algumas experiências do Projovem Urbano. O resultado da pesquisa aponta na direção de que o signo da formação inicial tem servido para mascarar a precarização da qualificação profissional para o trabalho simples.

Palavras-chave educação de jovens e adultos; Projovem Urbano; qualificação profissional; formação inicial; política educacional.
Abstract The first decade of the $21^{\text {st }}$ century is particularly important for Brazilian education because it records the growth of the government policies aimed at youth and adult workers. Specifically, after the creation of the National Youth Inclusion Program (2005), the relationship between government policies and professional education becomes part of the integrative promise of hegemonic education to reduce social inequalities. In this direction, Projovem Urbano establishes, in its pedagogical practices, the initial training in an arc of occupations so that workers can respond to the demands of productive restructuring, thus reducing the unemployment crisis. Therefore, the objective of the present study consisted in apprehending the concrete reality about the initial training for work, from a categorial frame, composed by some experiences of the Projovem Urbano program. The result of the research points in the direction that the guise of the initial training has served to mask the precariousness of the professional qualification for the simple work.

Keywords youth and adult education; Projovem Urbano; professional qualification; initial formation; educational policy. 


\section{Introdução}

O limiar do século XXI ficou marcado na história da sociedade brasileira por registrar mudanças significativas no contexto político-econômico e social, em decorrência da alternância entre os setores mais conservadores do bloco no poder, consagrando um membro da classe trabalhadora para governar o país. Esse período registrou a eleição do Presidente Lula da Silva (20032010), destacando-se pela recuperação do quadro de instabilidade econômica causado pelos antecessores neoliberais, fazendo com que o capitalismo brasileiro voltasse a apresentar taxas mais altas de crescimento. Em consequência de uma ampla base de sustentação política, o governo restabeleceu a participação popular através da consagração de direitos sociais e do poder de compra da classe mais pauperizada, via transferência de renda.

Emergiu, então, um período 'neodesenvolvimentista' de crescimento econômico, em que as diversas frações de classe passaram a reivindicar reformas orientadas para o mercado. Resumidamente, “o neodesenvolvimentismo é o desenvolvimentismo da época do capitalismo neoliberal" (p. 6), que dadas as condições históricas vigentes nas três últimas décadas do século passado, "resultou nas denominadas reformas orientadas para o mercado: abertura dos mercados de bens, de serviços e financeiros dos países periféricos; proeminência dos circuitos de acumulação financeira; privatização das empresas e serviços públicos; supressão de direitos trabalhistas e sociais" (Boito Jr., 2012, p. 6-7, grifo do autor). Nessa direção, o governo promoveu intensas reformas econômico-sociais, "criando condições para a construção de uma frente política que abarcasse setores das classes dominantes e das classes dominadas" (Boito Jr., 2012, p. 5).

Na área da educação, o governo do Partido dos Trabalhadores (PT) criou o Programa Nacional de Inclusão de Jovens (2005), reconfigurando a educação de jovens e adultos em meio à promessa integradora do slogan 'oportunidade para todos' (Brasil, 2008b, p. 13). Nessa direção, resgatou a teoria do capital humano sob o discurso do protagonismo juvenil e da formação de competências para combater o desemprego, incentivando à educação profissional baseada em itinerários formativos e arcos ocupacionais.

O programa, entretanto, teve de ser reestruturado visando à ampliação das oportunidades educacionais através da mudança dos critérios de elegibilidade. A lei n. 11.129, de 30 de junho de 2005 deu lugar a lei n. 11.692, de 10 de junho de 2008 (a), tendo por objetivo atender às diversas frações da classe trabalhadora por meio do Projovem Urbano; do Projovem Adolescente; do Projovem Trabalhador; do Projovem Campo - Saberes da Terra e do Projovem Prisional. Porém, "por se tratar de uma reformulação do Programa Projovem, os objetivos, fundamentos legais, princípios orientadores e estratégia curricular do Projovem Urbano permanecem os mesmos" (Brasil, 2008c, p. 1). 
Segundo o parecer do Conselho Nacional de Educação da Câmara de Educação Básica (CNE/CEB) n.18, o programa tem por objetivo a elevação de escolaridade, visando à conclusão do ensino fundamental, a qualificação profissional, em nível de formação inicial, "voltada a estimular a inserção produtiva cidadã e o desenvolvimento de ações comunitárias com práticas de solidariedade, exercício da cidadania e intervenção na realidade local" (Brasil, 2008c, p. 2).

No decorrer dos anos, o Projovem Urbano foi se constituindo como política dominante de formação da força de trabalho, tendo em vista que, as poucas oportunidades de acesso aos cursos profissionalizantes gratuitos favoreceram a grande aceitação da política de governo ${ }^{1}$. Nessa direção, o presidente Lula veio construindo o terreno fértil das ideias para justificar suas 'verdades', por meio de programas de governo direcionados à formação profissional, de modo que o trabalhador conseguisse preparar-se para competir em condições de igualdade no mercado de trabalho.

Sobre a verdade, ou seja, sobre dizer a verdade em política. É opinião muito difundida em alguns ambientes (e esta difusão é um sinal da estatura política e cultural desses ambientes) que é essencial à arte política mentir, saber esconder astuciosamente as próprias opiniões verdadeiras e os verdadeiros fins para os quais nos orientamos, saber fazer com que se acredite no contrário do que realmente se quer etc, etc. A opinião é tão enraizada e difundia que, ao se dizer a verdade, não se consegue crédito (Gramsci, 2007, p. 224).

Na dialética de Gramsci (2007), a 'verdade' em política 'dilui-se' no senso comum, escondendo os verdadeiros fins e interesses a que são destinados. Então, é por meio das ações políticas que o governo institui sua visão de mundo, sua ideologia e seu projeto de sociedade.

Nessa direção, o ineditismo da política educacional, em vez de buscar a ruptura com os ideais neoliberais, promoveu o reformismo da educação de jovens e adultos, investindo na educação profissional de modo a responder à reestruturação produtiva, representando a negação do trabalho como fundamento ontológico, para defender a formação do 'cidadão' produtivo, passivo e conformado a sua condição de classe. Cada vez mais o discurso do protagonismo juvenil torna-se o embrião desse processo para formar trabalhadores mais adaptados à economia globalizada. Nesse programa, o governo vem priorizando a formação inicial para o trabalho, propondo ações que na prática não têm modificado a realidade concreta dos trabalhadores e que, no máximo, têm possibilitado 'uma' ou 'outra' inserção profissional.

Dessa forma, a justificativa do estudo se evidencia pelo fato de os jovens e adultos trabalhadores ainda se constituírem protagonistas na crise 
do desemprego, num momento de reafirmação das contradições do capital. A hipótese é de que essa proposta de qualificação profissional assume um novo sentido, mascarada sob o signo da formação inicial, pois, devido às condições precarizadas de oferta e formação para o trabalho simples, não têm modificado o quadro geral das desigualdades sociais. Portanto, o objetivo foi investigar a "formação inicial" para o trabalho, buscando apreender o movimento real da formação profissional, ou seja, a realidade entre o discurso, a teoria e a prática, com base em dados de pesquisas com o Projovem Urbano.

Nesse sentido, realizamos uma pesquisa qualitativa, construindo um quadro categorial, utilizando fontes primárias e secundárias, visando apreender o movimento real da política de formação inicial para o trabalho, já que existem muitas interrogações sem respostas. Dentre as quais: em que se fundamenta a proposta de qualificação profissional do Projovem Urbano? Qual o 'sentido' da formação inicial em um arco de ocupações? O que apontam os estudos no campo educacional, realizados por meio de experiências com o programa?

Segundo Thompson (2002),

a experiência modifica, às vezes de maneira sutil e às vezes mais radicalmente, todo o processo educacional; influencia os métodos de ensino, a seleção e o aperfeiçoamento dos mestres e o currículo, podendo até mesmo revelar pontos fracos ou omissões nas disciplinas acadêmicas tradicionais e levar a elaboração de novas áreas de estudo" (Thompson, 2002, p. 13).

De acordo com Kuenzer (2006),

é possível confrontar as concepções e propostas presentes nas políticas com dados de pesquisa a partir de um quadro categorial epistemologicamente integrado, de modo que se apreendam as mediações que articulam as propostas educativas e a realidade do trabalho no âmbito da acumulação flexível (Kuenzer, 2006. p. 879).

Do ponto de vista metodológico, “é preciso superar o que se poderia chamar de leitura ideológica da ideologia que confrontam diferentes interpretações da realidade no nível subjetivo, o que vale dizer, diferentes pensamentos, sem que se tome a prática social como referência de análise" (Kuenzer, 2006, p. 879).

O método utilizado é o materialismo histórico-dialético, por entendermos ser o que melhor identifica as contradições da sociedade civil, na qual os homens entram em relações determinadas, independentes da sua consciência, relações essas que são necessárias à reprodução da sua própria existência. Marx (2008), em seus estudos sobre a sociedade civil, concluiu que as relações sociais são determinadas pelas relações materiais, incidindo sobre a consciência dos indivíduos, naturalizando as relações de produção. 
Para o autor, “a anatomia da sociedade deve ser procurada na economia política" (p. 47), tendo em vista que "na produção social da própria existência, os homens entram em relações determinadas, necessárias, independentes de sua vontade; estas relações de produção correspondem a um grau determinado de desenvolvimento de suas forças produtivas materiais" (Marx, 1982, p.47).

Na sequência, o artigo está dividido em três partes, além das considerações finais. Assim, inicialmente, contextualizaremos historicamente o Projovem Urbano, analisando os rumos e caminhos controversos que têm conduzido ao seu 'esvaziamento'. Na segunda parte do estudo, a proposta de qualificação profissional na legislação do programa, sob o signo da formação inicial, confrontada com a perspectiva do materialismo histórico-dialético. Por último, e não menos importante, construiremos um quadro categorial, epistemologicamente integrado, que possibilite apreender o movimento real do Programa, ou seja, as experiências e implicações que resultaram da prática social em construção.

Portanto, a análise de dados empíricos permitirá identificar o movimento real do programa, mesmo certo de que, por ser um produto do pensamento político neoliberal, tal proposta não tenha por objetivo romper com a ordem social vigente.

\section{Os rumos (in)certos do Projovem Urbano}

Segundo Boito Jr. (2003), “a conjuntura política brasileira é particularmente difícil para as correntes socialistas e progressistas", tendo em vista os rumos político-econômicos controversos do PT. Para o autor, “o governo Lula, que gerara alguma expectativa positiva em parte da esquerda brasileira e internacional, revelou-se uma espécie de 'terceira via' da periferia, disseminando a perplexidade, a decepção e a revolta entre trabalhadores e intelectuais" (Boito Jr., 2003, p. 10).

Nessa direção, o PT decepcionou quando optou pela manutenção da política econômica, uma vez que os membros do governo não tocaram na herança neoliberal de Fernando Henrique Cardoso. Para o autor, “o neoliberalismo propõe uma espécie de cidadania dual e a alta classe média avalia que os seus interesses são mais bem atendidos por essa proposta que pela expansão - custosa e desnecessária para ela - dos serviços públicos e dos direitos sociais" (Boito Jr., 2003, p.13).

Na visão do autor, a cidadania dual possibilita a concessão de alguns direitos sociais, marcados pelas condições mínimas de oferta dos serviços públicos, atendendo precariamente a classe trabalhadora de modo a atenuar os efeitos das desigualdades sociais.

A alta classe média tem razões econômicas para ver com bons olhos essa nova cidadania, que cria uma dualidade, em áreas como saúde, educação e previdência, 
entre, de um lado, um ramo público decadente, voltado para os trabalhadores de baixa renda, e, de outro lado, um ramo privado em expansão, voltado para a burguesia e demais setores de alto rendimento. Essa cidadania dual reproduz a posição privilegiada ocupada pela alta classe média, assegurando-lhe, por exemplo, melhor formação escolar e uma espécie de reserva de mercado dos postos de trabalho mais bem remunerados (Boito Jr., 2003, p. 13).

A cidadania apresenta-se, desse modo, revestida por um caráter ideológico que vai dissuadir a classe trabalhadora para uma nova forma de pensar, instituindo um conjunto de noções e significados que mascaram as novas formas de dominação simbólica sobre os verdadeiros interesses da classe dominante. Entretanto, os setores da classe dominada que compuseram à frente neodesenvolvimentista, ou seja, o operariado urbano e a baixa classe média, tiveram no PT um instrumento partidário e político para conseguirem ser representados, em parte, defendendo interesses e conquistando direitos. Para os autores, "os trabalhadores desempregados, subempregados, vivendo do trabalho precário ou 'por conta própria' representam o ponto extremo da frente neodesenvolvimentista" (Boito Jr. e Berringer, 2013, p. 33).

De acordo com os autores, essa massa marginal está dividida em dois setores: um organizado politicamente, chamado de movimentos de urgência (movimentos sociais por moradia, emprego etc.); e outro, desorganizado politicamente (beneficiários das políticas de transferência de renda), residindo principalmente na periferia dos grandes centros urbanos e no interior da Região Nordeste (Boito Jr. e Berringer, 2013, p. 33). Ainda segundo os referidos autores, "eles formam uma base eleitoral desorganizada e passiva que é convocada a intervir no processo político, apenas por intermédio do voto, para sufragar os candidatos da frente neodesenvolvimentista" (Boito Jr. e Berringer, 2013, p. 34).

Nesse cenário, o governo buscou oferecer condições de igualdade aos desiguais, priorizando a qualificação profissional da força de trabalho juvenil através de políticas compensatórias de alívio à pobreza, atendendo parte dos pauperizados, de baixa escolaridade e desorganizados politicamente, criando o Projovem Urbano, de modo a responder por escolarização, qualificação profissional e transferência de renda, resgatando, ainda que no limite, a noção de cidadania. Na abordagem pedagógica do governo, o conceito de cidadania desloca o sentido de 'sujeito histórico de direitos' para a noção de 'protagonismo juvenil', pois, em conjunto, "essas noções propiciam que o jovem se torne protagonista de sua inclusão social, na perspectiva da cidadania" (Brasil, 2008b, p. 13).

Os valores implícitos da cidadania dual estão expostos no currículo integrado, no qual o protagonismo juvenil emerge como mais um conceito que tira a responsabilidade do Estado na criação de empregos, haja vista que o 
Projovem Urbano fornece a certificação profissional sem encaminhar para o mercado de trabalho, deixando o trabalhador a própria sorte.

O Programa trabalha na perspectiva de contribuir especificamente para a reinserção do jovem na escola; a identificação de oportunidades de trabalho e qualificação profissional inicial dos jovens para o mundo do trabalho; a oferta de oportunidades de desenvolvimento de vivências desses jovens em ações comunitárias; e o acesso dos seus participantes à inclusão digital como instrumento de inserção produtiva e de comunicação. (Brasil, 2008, p. 5).

Assim, chama atenção a perspectiva totalizante do programa, dado que o econômico e o social se confundem estrategicamente, tendo em vista que o próprio indivíduo deve "identificar as oportunidades de trabalho". Dentre os objetivos do programa, espera-se que os trabalhadores sejam capazes de "desenvolver competências necessárias para o desempenho de uma ocupação que gere renda" (Brasil, 2008b, p. 67). Nesse sentido, o Projeto Pedagógico Integrado do Projovem Urbano defende a 'empregabilidade' fundamentada nas possibilidades do trabalho informal, autônomo, temporário, ou mesmo, do 'empreendedorismo', como se o trabalhador tivesse as mesmas condições de concorrer com outros capitalistas.

O que está em jogo é uma nova perspectiva de cooperação interdisciplinar, voltada para o desenvolvimento de saberes, conhecimentos, competências e valores de solidariedade e cooperação condizentes com o século XXI. Assim, frente à globalização dos mercados, redesenha-se o mundo do trabalho, constrói-se uma nova cultura de formação que deve permitir ao jovem tanto se adequar às demandas do mercado de trabalho quanto buscar formas de empreendedorismo individual, cooperativo e associativo (Brasil, 2008b, p. 58).

Dessa forma, o projeto integrado tem apontado no caminho inverso da formação humana e do desenvolvimento integral do trabalhador na sua condição ontológica, pois, tem sido executado nos mesmos moldes de outras experiências de escolarização, constituindo-se, na expressão mais conservadora, de uma educação fragmentada que, no máximo, equaciona o problema da exclusão por meio das oportunidades de escolarização. Segundo Pochmann; Ferreira (2016),

as políticas educacionais são orientadas para dar um suposto equilíbrio razoável entre a inclusão e a exclusão dos jovens, já que não existe um projeto que integra o conjunto das ações econômicas e sociais diretamente ligados aos problemas enfrentados pelos jovens na sociedade globalizada (Pochmann e Ferreira, 2016, p. 1.243). 
Nesses anos de duração do programa, a realidade material do Projovem Urbano tem mostrado o caráter falacioso da sua proposta, principalmente por conta da baixa qualidade social da formação inicial e da apropriação do programa pela "pequena política"2 (Gramsci, 2007), marcadas pelo grande índice da evasão escolar. O autor resume o conceito "grande política-pequena política" como sendo "política criativa e política de equilíbrio, de conservação, mesmo em se tratando de conservar uma situação miserável" (Gramsci, 2007, p. 345). Nesse sentido, o autor resgata o binômio conceitual para mostrar o predomínio de uma ou outra forma de fazer política, demonstrando como se desenvolviam as relações de poder no interior da classe política italiana, restando para os trabalhadores os programas que visavam à manutenção da ordem social. Segundo o filósofo italiano, é grande política lutar pela defesa ou manutenção de determinadas estruturas orgânico-sociais, reduzindo tudo à pequena política. Para isso, remete às questões relativas ao estabelecimento de prioridades, das diversas frações de uma mesma classe, predominando sobre os interesses gerais.

No Brasil, da mesma forma, a classe dominante tem se apropriando da "pequena política" para defender seus interesses na sociedade civil. No caso da reforma educacional, a ideologia dominante tem manifestado sua apreciação pela teoria do capital humano como pressuposto da inclusão social, mascarando suas 'verdades' em meio a números absolutos sobre as diversas experiências de escolarização do Projovem Urbano.

Partindo do contexto histórico recente, os números disponibilizados têm demonstrado a redução drástica de alunos interessados na formação inicial para o trabalho. Por exemplo, se compararmos o número de capitais que ofereceram o programa, entre 2006 e 2007, “o arco de ocupações mais presente foi o de Construção e Reparos, que tem duas modalidades e foi adotado em 19 das 27 capitais. O arco de Turismo e Hospitalidade foi oferecido em outras 17 capitais e o de Telemática, em 14" (Brasil, 2008b, p. 34).

Nesse sentido, os números do governo demonstram que o Projovem original esteve presente em todos os estados. Ao compararmos os números registrados no Projeto Pedagógico Integrado de 2008 com os do relatório de gestão de 2010, responsável pela avaliação do biênio 2008 e 2010, observaremos uma queda do número de estados atendidos, de 27 para 22, sem contar os municípios que não conseguiram assinar ou renovar a proposta de adesão.

O Projovem Urbano teve como meta para o período de 2008 a 2010 o atendimento a 900 mil jovens em todo o país. Até o momento, 118 entes federados já aderiram ao Programa: 96 Municípios com população igual ou superior a 200 mil habitantes e 22 Estados, que atendem municípios com menos de 200 mil habitantes, o que representa 825.374 jovens a serem beneficiados (Brasil, 2011, p. 10). 
Contudo, a promessa integradora não se materializou. O governo alegou que em razão da crise financeira que se instalou em todo o mundo ao final de 2008, “essa meta acordada de mais de 800 mil jovens tem sido constantemente revista pela Secretaria-Geral/PR e provavelmente não será alcançada no período previsto. Em decorrência desse fato, entre 2008 e 2010, 491.500 jovens foram matriculados no Programa" (Brasil, 2011, p. 10).

Segundos dados da Secretaria de Políticas Públicas, disponibilizados por meio da Lei de Acesso à Informação, o Projovem Urbano está sendo desenvolvido em 15 capitais, sendo 91 adesões municipais e 6 adesões estaduais (SECADI/MEC, Julho/2017). Entretanto, encontramos divergências quanto às informações sobre o município de São Vicente, pois, identificamos, através de visita à coordenação do programa, que a adesão do município não ocorreu por falta de interesse dos trabalhadores. Por meio dessa experiência, acreditamos que a realidade concreta do Projovem Urbano pode ser ainda mais grave, tendo em vista que a desatualização das informações do órgão gestor do executivo federal pode revelar um cenário ainda mais controverso.

Por outro lado, nota-se que o relatório da Secretaria Nacional da Juventude 2010, não faz menção ao índice 'efetividade social', exaltando somente a questão da oferta e da matrícula, demonstrando que o Estado carece de instrumentos para avaliar a efetividade social das políticas públicas. Nessa direção, os relatórios demonstram não existir uma política pública de avaliação institucional dos programas sociais para identificar mudanças na realidade material da classe trabalhadora. Não podemos, portanto, pensar a educação de jovens e adultos trabalhadores dissociada de um projeto societário de desenvolvimento desigual e excludente, já que "é necessário reconhecer que qualquer leitura que se faça acerca da educação profissional, inclusive de suas práticas pedagógicas, pressupõe uma opção política pautada no projeto de sociedade que se toma como referência" (Araújo, 2010, p. 3).

Nesse sentido, o Projovem Urbano peca por não viabilizar a avaliação da qualificação profissional, justificando suas ações sob o signo da 'formação inicial', apresentando-se nos limites de uma formação para o trabalho simples. Então, a seguir, discutimos o conceito de trabalho simples/trabalho complexo, de modo a elucidar as dicotomias em torno da formação inicial em um arco de ocupações.

\section{O trabalho simples no Projovem Urbano: do discurso ao simulacro da formação profissional}

O Programa Nacional de Inclusão de Jovens ${ }^{3}$ foi autorizado como curso experimental, de acordo com o parecer CNE/CEB n. 18/2008. O referido programa “integra a Educação de Jovens e Adultos e a Educação Profissional, toman- 
do o trabalho como princípio educativo". De acordo com o documento, "é o resultado da integração e articulação entre ambas, concebido como uma alternativa de inclusão social de jovens excluídos da escola e do trabalho" (Brasil, 2008c, p. 4). De modo que, "essa inclusão social se dará pela elevação dos níveis de escolaridade, pela sua qualificação inicial para o trabalho e pela sua participação cidadã que busca incluí-los, social e culturalmente, como cidadãos atuantes" (Brasil, 2008c, p. 4).

Na abordagem metodológica do programa, “a educação e a certificação para o trabalho serão planejadas de forma a compor itinerários formativos por arcos ocupacionais, viabilizando a programação da qualificação para o trabalho" (idem; alínea b e c). Portanto, “o Projovem Urbano será um programa educativo com organização curricular que trabalha de forma integrada todos os componentes curriculares, sem a clássica separação entre teoria e prática" (Brasil, 2008, p. 4, alínea d).

De acordo com o parecer CNE/CEB n. 18/2008, “a qualificação profissional inicial para o trabalho deverá possibilitar novas formas de inserção produtiva, com a devida certificação, correspondendo, na medida do possível, tanto às vocações dos jovens, quanto às necessidades e potencialidades econômicas, locais e regionais". (Brasil, 2008b, p. 5).

Segundo o documento, "o desenvolvimento das atividades previstas implicará na dedicação intensiva dos jovens ao curso por, pelo menos, 26 horas semanais"(...)"as horas presenciais (20 horas semanais) incluem as atividades em sala de aula, visitas, pesquisas de campo, participação em palestras, práticas relacionadas ao campo de qualificação profissional e à participação cidadã, sob a supervisão de um educador" (Brasil, 2008c, p. 6).

O Projeto Pedagógico Integrado toma, como ponto de partida, a necessidade da formação de um trabalhador flexível para responder à reestruturação produtiva, defendendo a qualificação profissional fundamentada em itinerários formativos, que propiciem à "formação inicial em um arco de ocupações", mascarando os novos sentidos sob as condições subjetivas para o trabalho.

Na concepção deste Programa, a Qualificação Profissional, considerando também a dimensão subjetiva do trabalho, remete ao desenvolvimento de habilidades, ao autoconhecimento, à sociabilidade, à realização pessoal, simultaneamente à preparação para uma inserção ocupacional, que possa assegurar renda aos jovens participantes e levá-los à autonomia (Brasil, 2008b, p. 154).

É justamente analisando as dimensões subjetivas da formação para o trabalho que poderemos identificar a qual projeto societário as políticas de governo atendem, ou melhor, para qual tipo de trabalho está orientada a formação inicial. Por exemplo, o Arco Ocupacional em Saúde tem por objetivo formar o trabalhador como auxiliar de administração em hospitais e clínicas, 
recepcionista de consultório médico e dentário, atendente de laboratório de análises clínicas, atendente de farmácia - balconista.

Dessa maneira, além de possibilitar uma formação para o trabalho de baixa qualidade social, uma vez que a formação não se ocupa com as singularidades e expertises de uma área específica, o trabalhador é excluído da possibilidade de escolher a profissão que melhor atenda aos seus interesses, haja vista que a opção de oferecer o arco ocupacional é do gestor (estado/município), viabilizando a escolha por meio de arcos ocupacionais, desde que tenha quórum para realizar a qualificação profissional. No caso da negativa, os trabalhadores são deslocados compulsoriamente para outro arco ocupacional, sob o dilema de ser excluído do programa. As condições subjetivas apontam que a opção do governo está direcionada à formação para o trabalho simples, atendendo a interesses locais e econômicos, deixando o trabalhador à própria sorte quanto às possibilidades de inserção produtiva.

Segundo Marx (2011), “o tempo de trabalho que custa produzir os meios de subsistência interessou, necessariamente, aos homens, em todas as épocas, embora em grau variável com o estágio de desenvolvimento" (Marx, 2011, p. 93).

Para Marx (2011), as relações sociais mascaram o valor que o trabalho agrega nas relações de produção, analogamente, não só a mercadoria, mas o próprio trabalho possui um duplo caráter que se manifesta como trabalho simples e trabalho complexo.

Dessa forma, o trabalho simples "mede-se pelo dispêndio da força de trabalho simples, a qual, em média, todo homem comum, sem educação especial, possui em seu organismo" (p. 66). Logo, "o trabalho simples médio muda de caráter com os países e estágios de civilização, mas é dado numa determinada sociedade". Por outro lado, "o trabalho complexo ou qualificado vale como trabalho simples potenciado ou, antes, multiplicado, de modo que uma quantidade dada de trabalho qualificado é igual a uma quantidade maior de trabalho simples" (Marx, 2011, p. 66).

Na visão do autor, independentemente do ofício ou do caráter útil, embora se constituam de atividades produtivas qualitativamente diferentes, "são apenas duas formas diversas de despender força humana de trabalho" (Marx, 2011 , p. 66), sendo empregadas para alcançar o desenvolvimento do conjunto das forças produtivas. Entretanto, o trabalho complexo, ou melhor, a força individual de trabalho por mais qualificada que seja tende a ser apropriada pelo capital, reduzindo a quantidade de trabalho complexo ao valor do produto do trabalho simples.

A experiência demonstra que essa redução sucede constantemente. Por mais qualificado que seja o trabalho que gera a mercadoria, seu valor a equipara ao produto do trabalho simples e representa, por isso, uma determinada quantidade de trabalho simples. As diferentes proporções em que as diversas espécies de trabalho 
se reduzem a trabalho simples, como sua unidade de medida, são fixadas por um processo social que se desenrola sem deles terem consciência os produtores, parecendo-lhes, por isso, estabelecidas pelo costume (Marx, 2011, p. 66).

O filósofo alemão demonstra que o duplo caráter do trabalho se manifesta como uma relação natural de subordinação ao processo social para o trabalho. Dessa maneira, a baixa conscientização sobre as diferentes proporções em que as diversas espécies de trabalho se reproduzem decorre também das condições materiais, intelectuais e físicas em que se encontram esses trabalhadores, não permitindo, em sua grande maioria, à necessária conscientização sobre a valorização entre o trabalho simples e complexo.

A diferença entre trabalho superior [complexo] e simples, entre trabalho qualificado e não qualificado decorre, em parte, de meras ilusões, ou pelo menos de distinções que cessaram de ser reais, mas sobrevivem convencionalmente, por tradições; em parte, se origina também da situação precária de certas camadas da classe trabalhadora, situação que as impede, mais que as outras, de reivindicarem e obterem o valor de sua força de trabalho (Marx, 2011, p. 231).

Para Marx (2011), a diferença entre trabalho simples e complexo decorre da especificidade e da habilidade que o trabalhador adquire no processo do trabalho. No trabalho simples, "o trabalhador deve possuir o grau médio de habilidade, destreza e rapidez reinantes na especialidade em que se aplica" (p. 229). Dessa forma, "o trabalho que se considera superior, mais complexo, é dispêndio de força de trabalho formada com custos mais altos, que requer mais tempo de trabalho para ser produzida, tendo, por isso, valor mais elevado que a força de trabalho simples" (p. 230).

Desta forma, "quando o valor da força de trabalho é mais elevado, emprega-se ela em trabalho superior e materializa-se, no mesmo espaço de tempo, em valores proporcionalmente mais elevados" (Marx, 2011, p. 230). O autor identificou as artimanhas que o capital desenvolve, por meio da educação, para agregar valor de uso ao processo produtivo. A força de trabalho que tem um conhecimento específico agrega um valor maior à mercadoria, de modo que o gasto advindo dessa qualificação para o trabalho complexo seja agregado ao valor total da produção.

A fim de modificar a natureza humana, de modo que alcance habilidades e destreza em determinada espécie de trabalho e se torne força de trabalho desenvolvida e especifica, é mister educação ou treino que custa uma soma maior ou menor de valores em mercadorias. Esta soma varia de acordo com o nível de qualificação da força de trabalho. Os custos de aprendizagem, ínfimos para a força de trabalho 
comum, entram, portanto, no total dos valores despendidos para sua produção (Marx, 2011, p. 202).

Na perspectiva de Marx (2011), "não importa ao processo de criação da mais valia que o trabalho de que se apossa o capitalista seja trabalho simples, trabalho social médio, ou trabalho mais complexo, de peso específico superior" (p. 230), toda forma de trabalho é apropriada pelo capital com o único objetivo de explorar o trabalhador. Como alerta o filósofo, "não devemos supor que o trabalho superior, qualificado, represente grande proporção do trabalho nacional" (Marx, 2011, p. 231).

Portanto, a apropriação da força de trabalho pelo capital tem por objetivo a reprodução das condições gerais de ampliação das relações de produção, financiadas pelas políticas de qualificação profissional do Estado.

\section{O signo da Formação Inicial para o trabalho simples}

A questão central sobre o signo da 'formação inicial' no Projovem Urbano somente pode ser apreendida, em sua essência, por meio das diversas experiências implementadas nos estados/municípios. A investigação que hora realizamos tem por metodologia a pesquisa qualitativa, baseada na análise do aporte teórico-metodológico do programa e do levantamento bibliográfico de estudos acadêmicos dos diversos matizes epistemológicos, cujo objeto de pesquisa tem por pressuposto o Projovem Urbano. Nessa direção, promoveremos a discussão entre o proposto e o executado, apreendendo o movimento real, pois, historicamente, nem sempre teoria e prática caminharam juntas nas políticas de governo.

Segundo Marx (2011), “a investigação tem de apoderar-se da matéria, em seus pormenores, de analisar suas diferentes formas de desenvolvimento e de perquirir a conexão íntima que há entre elas. Só depois de concluído esse trabalho é que se pode descrever, adequadamente o movimento real" (Marx, 2011 , p. 28). Nesse sentido, perquirirmos as conexões íntimas que delimitam os limites da qualificação profissional sob o signo da formação inicial, haja vista que muitas questões carecem de respostas e as estatísticas acabam esbarrando nas disputas de interesses políticos locais e regionais (Rummert, Bílio e Gaspar, 2017).

De acordo com Gaspar (2017), existe uma lacuna a ser preenchida pelo governo, no sentido de realizar um estudo longitudinal para sabermos efetivamente, até que ponto, os investimentos do Projovem Urbano conseguiram atender às expectativas da classe trabalhadora (Gaspar, 2017, p. 154). Segundo Duarte et al. (2009), "por avaliação de efetividade, entende-se, usualmente, o exame da relação entre a implementação de determinado programa/política 
e seus efeitos em termos de uma mudança nas condições sociais prévias da vida do público alvo" (Duarte et al., 2009, p. 13). Entretanto, “o indicador do Projovem na modalidade Urbano é a relação percentual entre o número de alunos certificados pelo Programa e o número de alunos aptos à certificação" (Brasil, 2011, p. 21).

Portanto, "a atitude mais adequada a se adotar, tanto do ponto de vista da produção do conhecimento quanto da ação político-prática, é a de vigilância crítica, buscando desvendar o sentido e o significado das palavras e dos conceitos, bem como perceber o que nomeiam ou escondem e que interesses articulam" (Frigotto e Ciavatta, 2006, p. 55).

No sentido da vigilância crítica, analisar as implicações dessa formação profissional consiste um compromisso ético-moral e político, especificamente, no que compete à qualidade social da proposta curricular. Conquanto, a formação inicial decorre da escolha de um arco ocupacional com até quatro ocupações que tenham base técnica comum, concebendo um novo sentido à formação profissional por meio de acesso e treinamento para o trabalho simples.

No que compete à execução, a qualificação profissional depende muito das condições objetivas e subjetivas, mesmo que teórico-metodologicamente, a carga horária seja considerada incipiente. Essas condições tornam-se determinantes para combater outro problema crônico: a evasão escolar, que se mostrou um elemento preocupante em todas as experiências do Projovem Urbano. A seguir, apresentaremos alguns estudos que corroboram nossa hipótese sobre o novo signo da qualificação profissional no contexto da reestruturação produtiva.

Duarte et al. (2009), constataram a distância entre a teoria e a prática na qualificação profissional do programa no Maranhão. Nas entrevistas realizadas com 27 jovens e adultos trabalhadores, "14 criticaram a promessa não cumprida pelo programa em relação à oferta de cursos de informática, idiomas e outros cursos profissionalizantes". De acordo com os autores, após a execução do programa, verificou-se a reação dos egressos como "promessas não cumpridas". Entre outros 7 jovens, 3 deles egressos, afirmaram que as informações não condiziam com a realidade prática do programa, 1 afirmou que supriu parcialmente as expectativas e outro afirmou que correspondeu totalmente, enquanto, 2 não se posicionaram" (Duarte et al., 2009, p. 93).

Moraes e Martins (2009), analisaram um grupo de 20 jovens, registrando as percepções dos jovens sobre a qualificação profissional nos arcos ocupacionais de Turismo, Agro-extrativismo, Construções e Reparos II (eletricista de edifícios, trabalhador da manutenção de edificações, instalador-reparador de linhas e aparelhos de telecomunicações instalador de sistemas eletrônicos de segurança) e serviços pessoais (cuidador de idosos, passador de roupas e lavadeiro e babá. Na investigação do Projovem Urbano/Maranhão, as autoras identificaram por meio de questionários que, quanto à escolha do arco ocupacional, 100\% responderam que tiveram a oportunidade de escolher. Contudo, 
o curso de agro-extrativismo não foi oferecido por questão da baixa procura, fazendo com que os poucos que escolheram fossem direcionados para o arco de Turismo (Moraes e Martins, 2009, p. 120).

De acordo com os autores, os alunos, ao serem perguntados se participaram do curso de qualificação profissional escolhido, 50\% responderam que participaram de forma integral (aulas teóricas e práticas), 40\% responderam que não tiveram aulas de qualificação e $10 \%$ responderam que só tiveram aulas teóricas, não chegando a concluir o curso de qualificação, pois, as aulas práticas não foram oferecidas. (p. 121). Ainda sobre os motivos que conduziram a não conclusão do curso, foram destacados pelos alunos: a falta de equipamentos para as aulas práticas; problemas com os convênios feitos com cursos profissionalizantes; a incompatibilidade das aulas com a disponibilidade dos alunos; a falta de professores para trabalhar na parte profissionalizante (Moraes e Martins, 2009, p. 122).

Na cidade de Salvador, Silveira (2009) investigou diversos fatores ligados a proposta de qualificação profissional, apresentando-se demasiadamente decepcionante junto aos egressos do programa. Segundo a autora, foi unânime os egressos se referirem a qualificação profissional como algo "inexistente, que não ocorreu, e onde ocorreu se tratava de conhecimentos excessivamente básicos não colaborando para um aumento de competências específicas sobre a área" (Silveira, 2009, p. 126). Segundo a autora, quando perguntados sobre a influência do Projovem e sua relação com o mundo do trabalho, "mais de $60 \%$ respondeu que não influenciou em nada/estava desempregado, apenas $10 \%$ respondeu que ter participado do programa ajudou a conseguir um emprego, e por volta de 3\% se refere a ganhos voltados para conhecimentos relacionados à qualificação profissional" (Silveira, 2009, p. 126).

Dentre as particularidades da qualificação profissional no Projovem Urbano, a legislação considera responsabilidade do gestor local, na contrapartida, a livre escolha do modus operandi para a execução dos arcos ocupacionais. Em alguns casos, esse processo ocorreu através de parcerias público-privadas, com organizações não governamentais (ONGs), escolas técnicas, por vezes, o Sistema $\mathrm{S}^{4}$, e até mesmo, institutos federais tecnológicos.

Embora as aulas de qualificação profissional aconteçam por meio de uma parceria com a Universidade Federal do Ceará - UFC e Instituto Federal Tecnológico do Ceará - IFCE, o que poderia representar a possibilidade de uma formação profissional de qualidade mais elevada, em virtude do envolvimento das renomadas instituições de ensino, este fato na verdade não resultava, segundo a opinião dos próprios alunos, em situação de contentamento. Na verdade, tal formação parece constituir motivo de frustração para grande parte dos alunos, pois, dentre os entrevistados na escola sob estudo, verificamos que apenas dois afirmaram gostar das aulas (Pires, 2011, p.110). 
De acordo com a pesquisadora, no Projovem Urbano/Fortaleza, o momento da abordagem sobre a qualificação profissional se mostrou como o mais tenso dos debates, quando observou muitas discordâncias entre os alunos, "alguns relatavam ter gostado muito e aprendido bastante. [...] Uma das alunas chegou a relatar que gostou de - aprender a fazer sanduíche, no Curso de Alimentação (Pires, 2011, p.110).

Para a autora, "além do aspecto enfatizado sobre as restritas opções de cursos ofertados na área profissional, os alunos relataram ainda sobre a baixa qualidade da formação profissional oferecida" (Pires, 2011, p.111). Dentre outras apreensões, conclui a autora, "conforme verificamos, frequentar esse curso parece não os preparar para as atuais exigências do mundo da produção, como também não assegura o ingresso no mercado de trabalho" (Pires, 2011, p.110).

Silva (2011), em estudo realizado no Projovem Urbano/João Pessoa (PB), registrou que a qualificação profissional, entendida pelos jovens como curso, "foi avaliada positivamente por $90 \%$ dos sujeitos". Entretanto, "ao lado dessa avaliação positiva, quase $1 / 3$ dos jovens diz não se sentir preparado para desenvolver um trabalho a partir dessa formação e; $20 \%$ do total dos sujeitos disseram que o curso não está se realizando como o esperado, apontando dificuldades como falta de material". Ainda, "entre os que se dizem preparados para exercer uma profissão a partir dessa formação (aproximadamente 60\% dos jovens), a metade afirma que já tem experiência ou curso anterior na disciplina" (Silva, 2011, p. 91).

Segundo a autora, embora o indicativo de profissionalização esteja presente no formato e na apresentação do Projovem Urbano, o que ele propõe efetivamente é qualificação profissional inicial, "mas os jovens não veem assim". Para autora, "a maneira como estes percebem a qualificação é como um curso, ou seja, pelo conceito que têm do que seja um curso, é que eles estabelecem compreensão sobre o que é a qualificação oferecida pelo Programa. Porque entendem eu vou aprender uma profissão por meio de um curso é que esperam que a qualificação lhes proporcione esse aprendizado" (Silva, 2011, p. 91).

Na acepção de Gondim (2011), a proposta de qualificação profissional do Projovem Urbano aponta para alguns equívocos, tais como: a) Não vinculação do Programa com o mercado de trabalho; b) Pouca contribuição dos Arcos Ocupacionais para o aprendizado dos concluintes; c) A insuficiente carga horária da Dimensão Qualificação Profissional, bem como daquela destinada à Ação Comunitária; d) O formato organizacional e ideológico do programa como política, pois coaduna com os parâmetros da política neoliberal, populista, assistencialista e focalizada, que é contrária à luta por uma política educativa universalista, travada com base na redemocratização do país na década de 1980; e) A forte incongruência que se revela na materialidade do 
programa como um equívoco perante uma política educativa profissionalizante (Gondim, 2011, p. 236).

De modo que, a formação profissional não caminha na direção de superar a condição marginal do trabalho assalariado no mercado de trabalho, ao contrário, a história se repete adquirindo novos sentidos e significados, pois, a formação inicial vem se constituindo numa possiblidade precarizada de profissionalização.

Corroborando nesse aspecto, Barros (2011), apreende os significados da qualificação profissional do Projovem Urbano/RJ, e constata que, com exceção de uma aluna,

os demais relatos ilustram uma qualificação profissional que só se realiza na teoria, não havendo a dimensão prática. Ou quando esta ocorre é de forma precária e inconsistente, pois mesmo estando previsto dentro da carga horária do curso, a realização de atividades práticas relacionadas ao campo da qualificação profissional não aparece nos depoimentos dos jovens entrevistados ou são realizadas de forma bastante reduzida (Barros, 2011, p. 92-93).

De acordo com a autora,

A qualificação profissional possui uma denominação de iniciação profissional. Mesmo assim, deixa muito a desejar visto que, como relata os entrevistados, eles ficaram sem ter aulas e também não tiveram oportunidade de realizar as visitas técnicas, ou seja, não realizaram atividades práticas, que seria uma oportunidade de vivenciar aquilo que aprenderam em sala de aula. E mais que isso motivar o jovem para que este busque formas de continuar a sua qualificação (Barros, 2011, p. 95).

Para Soares (2013), os jovens entraram no programa com uma maior expectativa em relação à qualificação profissional e saíram dele com essa expectativa diminuída. Questionados sobre se os conhecimentos obtidos facilitaram para encontrar trabalho ou ter maior qualificação para o mercado, 56\% responderam que não. Do restante, $33 \%$ das respostas afirmaram que sim, bastante; $11 \%$ dos respondentes afirmaram que sim, mas que outros cursos que fizeram posteriormente foram mais importantes (Soares, 2013, p. 129).

Nesse sentido, todos os participantes da pesquisa tinham feito aulas teóricas e práticas de qualificação profissional. Em João Pessoa, “a diminuição de expectativas após a qualificação profissional não se deu pela ausência do curso (como no caso das aulas de informática na primeira turma), mas pelo real efeito que essa dimensão teve na vida de quem o concluiu". Para essa conclusão, a autora partiu da seguinte pergunta: “Em sua opinião, o ProJo- 
vem contribuiu em sua vida para que? Do total de respostas, $11 \%$ afirmaram que o programa contribuiu para conseguir um emprego, enquanto a maioria respondeu 'aumentar minha autoestima' e 'ampliar os meus conhecimentos e amizades" (Soares, 2013, p. 130-131).

Para Santos et al. (2013), a precarização da qualificação profissional consistiu no principal motivo do aumento da evasão no programa. Em relação às aulas de informática, “100\% dos jovens responderam que acharam ruim, isso porque, no início das aulas do Programa foi informado que haveria aulas de informática, porém a escola não tinha sala para a realização destas aulas, 18 meses se passaram e as aulas de informática não aconteceram" (p.11-12). Na conclusão do estudo, os autores verificaram uma fragilidade na finalidade maior do Programa, "proporcionar a formação integral para os jovens" (Santos et al., 2013, p. 15).

O mercado de trabalho brasileiro tem sido caracterizado por um contingente de pessoas certificadas e igualmente desqualificadas para suprir as demandas mais urgentes das diversas formações profissionais que surgem com o advento da reestruturação produtiva, sendo direcionadas ao prolongamento da cadeia produtiva através do trabalho informal, autônomo, terceirizado, quarteirizado etc., por meio de vagas provisórias e mal remuneradas. E todo esse ciclo, repete-se de forma acentuada nos jovens e adultos trabalhadores, dependentes dos programas de governo (sazonais e transitórios), cujas características têm aumentado o número de desempregados, reproduzindo e desvalorizando a força de trabalho socialmente necessária à produção do capital.

O Projovem Urbano tem se constituído como programa à margem do Sistema Nacional de Educação, reafirmando a condição subalterna dos jovens e adultos trabalhadores, configurando novos caminhos para perpetuar velhos interesses, ressignificando a qualificação profissional para o trabalho simples, por meio do signo da formação inicial.

Nesse sentido,

a proposta de qualificação profissional é uma das contradições mais significativas do programa, uma vez que o direito à educação acaba sendo subsumido através das formas mais variadas, quando nos deparamos com a falta de estrutura física dos laboratórios de informática, das oficinas dos arcos ocupacionais, a falta de professores etc. (Gaspar, 2017, p. 161).

A marca da precarização mostrou-se presente de diversas formas, utilizando o signo da formação inicial para justificar a baixa qualidade social dos conteúdos, a fragmentação e a flexibilização da formação profissional, tornando os trabalhadores jovens e adultos reféns da pequena política, afinal, “encontramos entraves em muitas experiências marcadas por práticas cliente- 
listas privatizantes, buscando por caminhos transversos, implementar práticas educativas no vácuo do até hoje inexistente Sistema Nacional de Educação" (Rummert, Bílio e Gaspar, 2017, p. 65).

Nessa direção, a "formação inicial em um arco de ocupações" se constitui em mais um exemplo de certificação “vazia" (Kuenzer, 2005), pois, não vem proporcionando condições objetivas e concretas para que essa fração de classe concorra às vagas mais disputadas do mercado de trabalho.

Portanto, no contexto da 'grande política', o Estado resgata parte da classe trabalhadora para exercer a cidadania, promovendo condições básicas de escolarização e certificação rápida para o mercado, em 18 meses, apropriando-se do Projovem Urbano como conquista histórica para consolidar a 'pequenapolítica' de manutenção dos direitos sociais.

\section{Considerações Finais}

No contexto geral das experiências analisadas, a precarização da qualificação profissional do Projovem Urbano ocorreu por meio de diversas condições de oferta que, em conjunto, foram determinantes para que a formação profissional dos trabalhadores não promovesse a redução das desigualdades individuais e regionais. Na prática, essas diversas condições têm limitado o significado da qualificação profissional, por não responder as necessidades dos jovens e adultos trabalhadores.

Quando as condições materiais (objetivas e subjetivas) são negadas, a formação inicial para o trabalho passa a ter um novo sentido, cada vez mais 'sintomático' das relações de produção, reforçando o caráter aviltante da exploração do homem pelo homem, por negar o trabalho como fundamento ontológico do ser humano. Dessa forma, a ausência da qualidade social da formação inicial também se materializa como ataque ao direito dos jovens e adultos trabalhadores.

Em que pese as possiblidades de acesso e escolarização, a proposta pedagógica 'integrada' não tem rompido com o estigma herdado historicamente pela educação de jovens e adultos trabalhadores, pois a formação inicial possibilita remotas condições técnico-profissionais de inserção produtiva. No máximo, configura possibilidades de 'uma' ou 'outra' inclusão em torno do trabalho precarizado, consoante às possibilidades de renda por meio do trabalho informal, parcial, terceirizado etc.

A configuração do Projovem Urbano, ou mesmo do Projovem Integrado como um todo, não supera limites de origem, quais sejam: o seu distanciamento do campo da EJA e o sistema educacional; o seu modelo de programa emergencial; sua proposta de qualificação profissional voltada para o exercício do trabalho simples; sua formação pragmática, que valoriza o "saber empreender-se"; e sua certificação 
destituída dos conhecimentos básicos exigidos por essa etapa de ensino, servindo à elevação dos indicadores de escolaridade da população (Ventura, 2011, p. 89).

Dessa forma, a relação entre teoria e prática da proposta pedagógica tem caminhado cada vez mais distante da perspectiva do governo, ou seja, "proporcionar a formação integral aos jovens, por meio de uma efetiva associação entre: Formação Básica, Qualificação Profissional e Participação Cidadã" (Brasil, 2008b, p. 42). De modo igual, as possiblidades de articulação entre os setores responsáveis por implementar, executar e avaliar as ações não têm conseguido avanços significativos, ficando cada qual responsável pela sua esfera de governo, consistindo a promessa de inclusão social, portanto, numa ideologia.

Mesmo o Programa Nacional de Inclusão de Jovens sendo considerado um avanço no que compete ao direito à educação, quando confrontados discurso, teoria e prática, na ponta do processo, sobressaem as contradições internas de um projeto pedagógico direcionado à formação para o trabalho simples. De acordo com os dados levantados, fica evidente que a política integrada de escolarização não modificou a condição geral de subalternidade da classe trabalhadora, pelo contrário, produziu novas percepções de mundo aos jovens e adultos trabalhadores por meio da dicotomia entre a teoria e a prática, da precarização da qualificação profissional, do aligeiramento da certificação profissional etc., resultando em mais uma promessa 'integradora'.

Lamentavelmente, o signo da formação inicial vem mascarando a precarização da qualificação profissional, resultando numa política invisível aos olhos daqueles que mais necessitam retornar ao mercado de trabalho. Portanto, o pensamento de Gramsci sobre dizer a verdade em política mostra-se atual, pois, entre o discurso e a prática, o Projovem Urbano não vem oportunizando condições concretas para realizar à inclusão social. Nesse sentido, as 'verdades' do Presidente Lula, às quais nos referimos no começo do texto, são revestidas por noções e significados que escondem astuciosamente os verdadeiros fins para os quais as políticas de governo têm sido orientadas. Esse cenário é elucidativo, pois, tais verdades foram proferidas e criadas sabendo que o Projovem Urbano não tinha por objetivo romper com a "grande política", notadamente, com o modo de produção capitalista. 


\section{PROJOVEM URBANO: LA PRECARIZACIÓN ENMASCARADA BAJO EL SIGNO DE LA FORMACIÓN INICIAL PARA EL TRABAJO SIMPLE}

Resumen La primera década del siglo XXI es particularmente importante para la educación brasileña por registrar el crecimiento de las políticas de gobierno dirigidas a los jóvenes y adultos trabajadores. Específicamente, después de la creación del Programa Nacional de Inclusión de Jóvenes (2005), la relación entre las políticas de gobierno y la educación profesional se vuelven parte de la promesa integradora de la educación hegemónica para la reducción de las desigualdades sociales. En esa dirección, el Projovem Urbano pasa a instituir, en sus prácticas pedagógicas, la formación inicial en un arco de ocupaciones para que los trabajadores consigan responder a las demandas de la reestructuración productiva, reduciendo, así, la crisis del desempleo. Luego, el objetivo de ese estudio consistió en aprehender la realidad concreta sobre la formación inicial para el trabajo, a partir de un marco categorial, compuesto por algunas experiencias del Projovem Urbano. El resultado de la encuesta apunta en la dirección de que el signo de la formación inicial ha servido para enmascarar la precarización de la calificación profesional para el trabajo simple. Palabras clave educación de jóvenes y adultos; Projovem Urbano; calificación profesional; formación inicial; política educativa.

\section{Referências}

\begin{abstract}
ARAÚJO, Ronaldo M. L. O Marxismo e a pesquisa qualitativa como referências para investigação sobre educação profissional. Disponível em: <http://www.estudosdotrabalho. org/anais-vii-7-seminario-trabalho-ret-2010/ Ronaldo_Marcos_Lima_Araujo_o_marxismo_e_a_ pesquisa_qualitativa_como_referencias_investigacao_educacao_profissional.pdf $>$. Acesso em: 10 ago. 2018
\end{abstract}

BRASIL. Câmara dos Deputados. Medida Provisória n. 238, de $1^{\circ}$ de fevereiro de 2005. Institui, no âmbito da Secretaria-Geral da Presidência da República, o Programa Nacional de Inclusão de Jovens - ProJovem, cria o Conselho Nacional de Juventude - CNJ e cargos em comissão, e dá outras providências. Disponível em: < http://www2.camara.leg. br/legin/fed/medpro/2005/medidaprovisoria238-1-fevereiro-2005-535573-norma-pe.html>. Acesso em: 11 ago. 2018

BRASIL. Presidência da República. Casa Civil. Subchefia para Assuntos Jurídicos. Lei n. 11.129, DE 30 de junho de 2005. Institui o Programa Nacional de Inclusão de Jovens - Projovem; cria o Conselho Nacional da Juventude - CNJ e a Secretaria Nacional de Juventude; altera a lei n. 10.683 , de 28 de maio de 2003, e a lei n. 10.429, de 24 de abril de 2002; e dá outras providências.

BRASIL. Ministério da Educação. Conselho Nacional de Educação. Parecer CNE/CEB n. 37 de 7 de julho de 2006. Aprovação de diretrizes e procedimentos técnico-pedagógicos para a implementação do ProJovem - Programa Nacional de Inclusão de Jovens: Educação, Qualificação e Ação Comunitária.

BRASIL. Presidência da República. Casa Civil. Subchefia para Assuntos Jurídicos. Lei $n$. 11.692, de 10 de junho de 2008. Dispõe sobre o Programa Nacional de Inclusão de Jovens - Projovem, instituído pela Lei n. 11.129, de 30 de junho de 2005; altera a Lei n. 10.836, de 9 de janeiro de 2004; revoga dispositivos das Leis nos 9.608, de 18 de fevereiro de 1998, 10.748, de 22 de outubro de 2003, 10.940, de 27 de agosto de 2004, 11.129, de 30 de junho de 2005, e 11.180, de 23 de setembro de 2005; e dá outras providências. 2008a. 
BRASIL. Secretaria Geral da Presidência da República. Secretaria Nacional da Juventude. Projeto Pedagógico Integrado do Projovem Urbano. Brasília. 2008b.

BRASIL. Ministério da Educação. Conselho Nacional de Educação. Parecer CNE/CEB $n$. 18, de 6 de agosto de 2008c. Apreciação do Projeto Pedagógico Integrado e autorização de funcionamento do Projovem Urbano.

BRASIL. Presidência da Republica. SecretariaGeral da Presidência da República. Secretaria Nacional de Juventude. Relatório de Atividades: Programa Nacional de Inclusão de Jovens (Projovem Urbano) - Ano Referência - 2008. Brasília, Jan. 2009.

BRASIL. Secretaria Nacional da Juventude. Relatório de Gestão do Exercício 2010. Mar. 2011.

BARROS, Denise S. Os significados da Educação Profissional para a trajetória profissional dos jovens oriundos do Projovem Urbano. 2011. 139f. Dissertação (Mestrado em Serviço Social) - Pontifícia Universidade Católica do Rio de Janeiro, Rio de Janeiro, 2011.

BOITO Jr., Armando. A hegemonia neoliberal no governo Lula. Revista Crítica Marxista, Campinas, São Paulo, v. 17, p. 10-36, 2003.

BOITO Jr., Armando. As bases políticas do neodesenvolvimentismo. Trabalho apresentado na edição de 2012 do Fórum Econômico da Fundação Getúlio Vargas, São Paulo.

BOITO Jr, Armando; BERIINGER, Tatiana. Brasil: classes sociais, neodesenvolvimentismo e política externa nos governos Lula e Dilma. Revista de Sociologia e Politica, Curitiba, v. 21, n. 47, p. 31-38, set. 2013.

DUARTE, Maria R. T. et al. Os desafios teórico-metodológicos e a avaliação de programas educacionais. In: DUARTE, Maria R. T. (Org.). Palavras de jovens sobre o Projovem: estudos com egressos e a formação de pesquisadores em avaliação de programas educacionais. Belo Horizonte: Ed. Escritório de Histórias, 2009. p. 9-31.
DUARTE, Maria R. T. Escolarização e trabalho: que efeitos são possíveis? In: DUARTE, Maria R. T. (org.). Palavras de jovens sobre o projovem: estudos com egressos e a formação de pesquisadores em avaliação de programas educacionais. Belo Horizonte: Ed. Escritório de Histórias, 2009. p. 75-105.

FRIGOTTO, Gaudêncio; CIAVATTA, Maria. Educar o trabalhador cidadão produtivo ou o ser humano emancipado?. In: FRIGOTTO, Gaudêncio; CIAVATTA, Maria (Org.). A formação do cidadão produtivo a cultura de mercado no ensino médio técnico. Brasília: Instituto Nacional de Estudos e Pesquisas Educacionais Anísio Teixeira, 2006. p. 55-70.

FRIGOTTO, Gaudêncio. Fundamentos científicos e técnicos da relação trabalho e educação no Brasil de hoje. In: LIMA, Júlio C. F.; NEVES, Lúcia M. W. (Org.). Fundamentos da educação escolar do Brasil contemporâneo. 2. reimp. Rio de Janeiro: Editora da Fiocruz, 2008b. p. 241-288.

GASPAR, Leandro. Projovem urbano: jovens e adultos como sujeitos históricos de um projeto societário excludente. Trabalho Necessário, Niterói, v. 15, n. 26, p. 142-165, 2017.

GONDIM, Edinólia P. Juventude e cidadania: na trilha da avaliação do Projovem em São Luís-MA. 2011. 273f. Tese (Doutorado em Educação) - Programa de Pós-Graduação em Educação da Faculdade de Educação da Universidade Federal da Bahia, Bahia, 2011.

GRAMSCI, Antonio. Cadernos do Cárcere: Maquiavel notas sobre o estado e a política. v. 3. 3. ed. Rio de Janeiro: Civilização Brasileira, 2007.

KUENZER, Acácia. Exclusão includente e inclusão excludente: a nova forma de dualidade estrutural que objetiva as novas relações entre educação e trabalho. In: LOMBARDI, Jose C.; SAVIANI, Demerval; SANFELICE, Jose L. (Org.). Capitalismo, trabalho e educação. 3. ed. Campinas: Autores Associados, 2005. p. 77- 95. 
KUENZER, Acacia Z. A educação profissional nos anos 2000: a dimensão subordinada das políticas de inclusão. Educação e Sociedade, Campinas, v. 27, n. 96, p. 877-910, out. 2006. Número Especial.

MARX, Karl. O Capital: crítica da economia política. 29. ed. Rio de Janeiro: Civilização Brasileira, 2011.

MARX, Karl. Contribuição à critica da economia política. 2. ed. São Paulo: Expressão Popular, 2008.

MORAES, Lélia C. S.; MARTINS, Talita J. S. A qualificação profissional no Projovem urbano sob a ótica dos egressos. In: DUARTE, Maria R. T. (Org.) Palavras de jovens sobre o Projovem: estudos com egressos e a formação de pesquisadores em avaliação de programas educacionais. Belo Horizonte: Escritório de Histórias, 2009. p. 107-128.

PIRES, Márcia G. L. Novos marcos de dualismo educacional na sociedade contemporânea: o caso do Projovem Urbano Fortaleza. 2011. 159f. Tese (Doutorado em Educação) - Universidade Federal do Ceará, Faculdade de Educação, Programa de Pós-Graduação em Educação Brasileira, Fortaleza-CE, 2011.

POCHMANN, Marcio; FERREIRA, Eliza B. Escolarização de jovens e igualdade no exercício do direito à educação no Brasil: embates do início do século XXI. Educação e Sociedade, Campinas, v. 37, n. 137, p. 1.241-1.267, out./dez., 2016.

RUMMERT, Sonia. Gramsci, trabalho e educação: jovens e adultos pouco escolarizados no Brasil atual. Cadernos Sísifo 4, Lisboa: Educa/ Universidade de Lisboa, 2007.

RUMMERT, Sonia; BÍLIO, Rafael; GASPAR, Leandro. Projovem urbano: a politica transitória e emergencial como marca sócio-histórica na educação de jovens e adultos. In: BONFIM, Maria I.; RUMMERT, Sonia (Org.). Educação de jovens e adultos da classe trabalhadora brasileira: "novos" projetos e antigas disputas. Curitiba: Editora CRV, 2017. p. 47-76.

SANTOS; Sandra R. B. Evasão Escolar no Projovem Urbano: algumas percepções em Vitória da Conquista - Ba (Etapa 2008 a 2010). In: ENCONTRO DE ADMINISTRAÇÃO POLÍTICA PARA O DESENVOLVIMENTO DO BRASIL, 4., Vitória da Conquista, Bahia. Anais...Bahia, 5 a 7 jun. 2013.

SILVA, Ângela C. F. Jovens e politicas públicas: representações sociais de educação entre jovens do ProJovem Urbano na cidade de João Pessoa /PB. 2011. 112f. Dissertação (Mestrado em Educação) - Universidade Federal da Paraíba, João Pessoa, 2011.

SILVEIRA, Olívia. O unicórnio e o rinoceronte: uma análise do Projovem a partir da percepção de seus beneficiários. 2009. $168 f$. Universidade Federal da Bahia. Dissertação (Mestrado em Educação) - Faculdade de Educação, Universidade Federal da Bahia, Salvador, 2009.

SOARES, Swamy P. L. Estado, politicas públicas e juventude: avaliação de efeitos de um programa federal na esfera local. 2013. Tese (Doutorado em Educação) - Universidade de São Paulo, São Paulo, 2013.

VENTURA, Jaqueline. A trajetória histórica da Educação de Jovens e Adultos. In: TIRIBA, Lia; CIAVATTA; Maria (Org.). Trabalho e educação de jovens e adultos. Brasília: Líber Livro; Niterói: EdUFF, 2011. p. 57-97.

THOMPSON, Edward P. Educação e experiência. In: THOMPSON, Edward P. Os românticos: a Inglaterra na era revolucionária. Rio de Janeiro: Editora Civilização Brasileira, 2002. p. 11-47. 